\title{
Spatial covariance reverses the compound effect of multiple stressors on rocky shore biofilm
}

\author{
Luca Rindi ${ }^{1}$, JIANYU HE ${ }^{1}$, and Lisandro Benedetti-Cecchi ${ }^{1}$ \\ ${ }^{1}$ University of Pisa
}

May 6, 2021

\begin{abstract}
Understanding how multifactorial fluctuating environments affect species and communities remains one of the major challenges in ecology. Here, we use field experiments and simulations to assess the influence of nonlinear effects and spatial covariation of two important climate variables - warming and sediment deposition - on the biomass and photosynthetic activity of rocky intertidal biofilm. Simulations stemming from an experimentally derived response surface showed how the degree and direction of spatial covariation between warming and sediment deposition ultimately determined the nonlinear response of biofilm biomass (but not photosynthetic activity) to fluctuating levels of the two climate variables. Experimental results corroborated these predictions, probing the buffering effect of negative spatial covariation against extreme levels of warming and sediment deposition. Together, these results indicate that consideration of local-scale patterns of covariation between climate drivers can improve our understanding and ability to predict ecological responses to ongoing and future changes in Earth's climate.
\end{abstract}

\section{INTRODUCTION}

Ecosystems face multiple interacting natural and human-driven disturbances whose occurrence, magnitude and impact vary in space and time (Jentschet al. 2009; Wernberg et al. 2013; (Gunderson et al. 2016). Predicting the ecological impacts of environmental fluctuations is of outstanding importance as anthropogenic climate change is already altering the frequency and intensity of climate extremes (Kirtman et al. 2013; Drijfhout et al. 2015). In the last two decades, laboratory and field experiments have documented strong ecological effects of environmental fluctuations on species and assemblages through changes in frequency, variance and autocorrelation of disturbance, resource supply or other variables (Benedetti-Cecchi 2003; Bertocciet al. 2005; Benedetti-Cecchi et al. 2006; Crain et al. 2008; Lawson et al. 2015; Gunderson et al. 2016; Bernhardt et al. 2018). One general mechanism that can explain these results is the prevalence of nonlinear response functions relating ecological and environmental variables. Nonlinear responses, where a change in the input can generate a disproportionate change in the output, are ubiquitous in nature (Zhang et al. 2015; Denny 2017). If $f(x)$ is a nonlinear function of an environmental variable $x$, nonlinearity causes a mismatch between the expected response under average conditions, $f(x)$, and the integrated response under variable condition, $f(x)$, such that $f(x) \neq f(x)$. This mathematical property of nonlinear functions is known as Jensen's inequality or nonlinear averaging (Jensen 1906). The sign of the inequality is positive (negative) for accelerating (decelerating) response functions, whereas the magnitude of change depends on the degree of non-linearity and the amount of variability in $x$ (Ruel \& Ayres 1999, Chesson 2012). Ecologists have successfully used Jensen's inequality to model the performance of produces and consumers under stressful and variable environmental scenarios (Ruel \& Ayres 1999; Benedetti-Cecchi 2005; Benedetti-Cecchi et al. 2012; Vasseuret al. 2014; Koussoroplis \& Wacker 2016; Denny 2017; Bernhardtet al. 2018).

Despite the widely recognised importance of environmental variability in influencing organisms' performance, few studies have explored the consequences of Jensen's inequality in a multifactorial context, incorporating 
the effect of covariation between variables (Pincebourdeet al. 2012; Koussoroplis \& Wacker 2016; Koussoroplis et al. 2019). The simultaneous effect of multiple factors may produce nonlinearities that would remain undetected in a unifactorial scenario (Koussoroplis et al. 2017). These nonlinearities may interact with environmental variance and with the degree and direction of the covariance among environmental factors, leading to a deviation between organism's performance under constant and variable conditions. Direct evidence of the role of covariance in modulating organisms' performance stems from recent laboratory and mesocosm experiments (Pincebourdeet al. 2012; Koussoroplis \& Wacker 2016; Koussoroplis et al. 2019). For instance, Koussoroplis and colleagues (2016) have shown how covariation between temperature and resource supply influenced the life-history traits of the water flea Daphnia magna. To what extent the variance and covariance between simultaneously fluctuating variables affect ecological assemblages under field conditions remains largely untested.

Rocky intertidal habitats have been extensively used as model systems to test cornerstone hypotheses in ecology and to unravel the influence of multiple interacting processes (Hawkins et al. 2020). Plant and animals living on rocky shores are exposed to a mosaic of environmental conditions where key variables such as temperature and wave action often covary at experimentally tractable spatial scales (Helmuth et al.2006; Lima \& Wethey 2012, Hawkins et al. 2020). The small size and short life span of many organisms living on rocky shores further facilitate the analysis of multiple stressors and their covariation in space or time. For example, recent studies have used epilithic microphytobenthos (hereafter, biofilm) to show how the temporal clustering of extreme events of warming and sediment deposition can promote legacy effects and drive populations to collapse (Dal Belloet al. 2017, 2019). These and other studies have documented strong negative effects of warming and sediment accretion following heavy rains on rocky intertidal organisms (Harley 2003; Vaselli et al. 2008; Kordas et al. 2015). Substratum complexity, generated by emergent surfaces mixed with heterogenous areas with depressions, cracks and crevices in the rock, can result in different patterns of spatial covariation between aerial temperature and sediment. For example, positive covariation may occur on emergent rocks on sunny days and calm sea, whereas cracks and crevices where sediment is more persistent during rough sea conditions may introduce negative covariation.

We used a combination of experimental and simulation approaches to evaluate how spatial covariation between two important climate variables, warming and sediment accretion following run-off, modulated the performance of rocky intertidal biofilm. As a first step, we used a response surface design involving 16 combinations of warming and sediment deposition to derive a response surface (henceforth RS) relating the biomass and photosynthetic activity of biofilm to the two variables in the field. Armed with an empirically derived RS, we used simulations to explore the performance of biofilm under different covariance scenarios of warming and sediment deposition. We expected the performance of biofilm to differ between constant and variable conditions owing to nonlinearities in the RS. Finally, we tested the predictions originating from our simulations in a second field experiment in which we manipulated the spatial correlation (positive or negative) and intensity of warming and sediment deposition in a factorial experiment. Our results provide the first empirical evidence of how spatial covariation between interacting stressors can modulate nonlinear averaging effects on primary producers in real-world conditions.

\section{METHODS}

\section{Study site}

The study was done along the coast of Calafuria (Livorno, $43^{\circ} 30^{\prime} \mathrm{N}, 10^{\circ} 19^{\prime} \mathrm{E}$ ) between March and December of 2017. The coast is composed of gently sloping sandstone platforms with high-shore levels $(0.3-0.5 \mathrm{~m}$ above mean low-level water) characterized by populations of barnacles interspersed among areas of seemingly bare rock, where biofilm develops. Biofilm at Calafuria is composed mainly by cyanobacteria of the genusRivularia , contributing up to $50 \%$ of the bacterial assemblage (Maggi et al. 2017) (Fig. S1a). As shown in a previous study, warming and sediment deposition following run-off are important drivers of biofilm biomass in this system (Dal Bello et al . 2017). Grazing by the littorinid snail Melarhaphe neritoides (L.) can also affect the abundance and distribution of the biofilm, mostly in late fall and winter (Dal Bello et al. 2017). 


\section{Experiment 1: Derivation of the response surface}

We used a response-surface experimental design involving 16 combinations of warming and sediment deposition to build a warming-sediment response surface (RS) for biofilms (Fig 1a). The experiment was conducted between May and August 2017. In May 2017, 68 plots consisting of patches of rock $40 \mathrm{x} 40 \mathrm{~cm}$ fully covered by biofilm were marked at their corners with raw-plugs inserted into the rock for future relocation. Four replicated plots were randomly allocated to each combination of four levels of warming crossed with four levels of sediment deposition. Temperature and sediment were manipulated following methodologies developed in previous studies (Dal Bello et al. 2017). The warming factor included a control (ambient temperature) and three levels of elevated temperatures $\left(+5{ }^{\circ} \mathrm{C},+10{ }^{\circ} \mathrm{C}\right.$ and $+15{ }^{\circ} \mathrm{C}$ above ambient levels). Plots were heated with aluminium chambers equipped with stoves (Fig. S1), with warming levels chosen to reflect a wide range of temperatures experienced by the biofilm at the study site, from common to rare. We characterized individual warming levels as the averaged return-time of positive thermal anomalies using a 66-yrs time series of temperature measurements (Appendix S1, Fig. S2). Positive temperature anomalies of $+5{ }^{\circ} \mathrm{C}$ are common during the central hours of the day and have a return time of less than $1 \mathrm{yr}$, while anomalies of $+10{ }^{\circ} \mathrm{C}$ have a return time of about $2 \mathrm{yrs}$. Anomalies of $+15{ }^{\circ} \mathrm{C}$ corresponded to extreme conditions with a return time of about $85 \mathrm{yrs}$. The warming treatment consisted of keeping the difference between the chamber and the ambient air temperature as close as possible to the designated treatment level for 2 hours (Fig. S1c and S3a-b). Aerial temperature was constantly measured with iButton loggers during the 2 hours of warming inside and outside the heating chambers. Three replicate plots were established as control for artefacts (CA) to assess the potential effect of shading on biofilm during the heating sessions. CA plots were shaded with cardboard chambers, but they were not warmed.

Sediment deposition included a control (no sediment added) and three levels of sediment accretion $(+0.5$ $\mathrm{cm},+1.0 \mathrm{~cm}$ and $+1.5 \mathrm{~cm}$ thick layers of sediment deployed over the plots), to mimic the effects of runoff following heavy rainfall events (Fig. S1d). Sediment layers about $0.5-1 \mathrm{~cm}$ thick originate naturally on flat rocks after intense storms ( $>70 \mathrm{~mm}$ within the previous $24 \mathrm{~h}$ ) and may persist for about $2 / 3$ days before being washed away by waves (Fig. S1b) (Dal Belloet al. 2017). In some areas, depressions on the rock may favour sediment accretion with the formation of mats up to $15 \mathrm{~mm}$ thick. We mimicked these events by adding to each designated plot a layer of sediment collected in the surrounding area and diluted in freshwater. Sediment thickness was measured with a calliper and adjusted accordingly to the nominal value of the sediment deposition treatment assigned to each plot (Fig. S3c). Warming was performed before sediment deposition, but the order in which the two stressors are imparted has no effects on the biofilm (Dal Bello et al. 2017). Experimental units were monitored in the 2-3 days following the treatment application and sediment levels were adjusted when necessary. Experimental treatments were applied only once as a single pulse; due to the impossibility of treating all the 71 plots on the same day, sets of 11-12 randomly chosen plots were treated in each of 6 days within a month.

Treatment effects were evaluated after 7, 14 and 21 days since the start of the experiment as changes in biofilm biomass and photosynthetic activity. Biomass was determined by means of an image-based remote sensing technique that uses chlorophyll $a$ concentration as a proxy $\left(\mu \mathrm{g} \mathrm{chl} a \mathrm{~cm}^{-2}\right)$. Chlorophyll $a$ was estimated from a ratio of reflectance at near-infrared (NIR) and red bands (Ratio Vegetational Index RVI) by means of a IR-sensible camera (ADC), following the method proposed by Murphy and colleagues (Murphyet al. 2009). NIR/red ratios are related to chlorophyll aby a linear relationship, calculated on the basis of laboratory chlorophyll $a$ extraction from Calafuria sandstone cores (Dal Bello et al. 2015). For each photo of a plot, 6 subplots of 128x128 pixels were haphazardly selected and biomass estimates were obtained for each pixel using a java-routine on ImageJ software (Schneider et al. 2012).

The physiological status of the photosynthetic apparatus of biofilm was assessed trough a portable underwater pulse-amplitude-modulated (PAM) fluorometer (Diving-PAM, Walz). Maximum photochemical efficiency after 5' of dark adaption (henceforth dark yield) and effective quantum yield of photosystem II in actinic light (henceforth light yield) were used as a proxy of photosynthetic efficiency and stress, respectively. Within each experimental plot, 3 and 6 measurements were haphazardly taken for light and dark yield, respectively. 
Sampling had an average duration of about $2 \mathrm{~h}$ and started around $2.5 \mathrm{~h}$ after sunrise and ended at midday. Dark yield measurements were taken after 5 minutes of dark adaptation, while light yield was measured under natural light condition.

We used a generalized additive model (GAM) to derive the RS from the experimental data.

We obtained a single RS for each response variable ( $\mathrm{Chl} a$, dark and light yield) by taking averages over the three sampling dates. Data were modelled as a function of three smoothers of nominal levels of warming $(W)$ and sediment deposition $(S)$ and their interactions $(W x S)$ (with identity link and Gaussian error distribution):

$Y_{\mathrm{ijk}} \sim \beta_{0}+s_{1}\left(W_{i}\right)+s_{2}\left(S_{j}\right)+\operatorname{te}\left(W \times S_{\mathrm{ij}}\right)+\varepsilon_{\mathrm{ijk}}$ Eq. 1

where the $Y_{i j k}$ is the value of the response variable (Chl $a$, dark and light yield) in replicate $k$, sediment level $j$ and warming level $i, \beta_{0}$ is the intercept, $s_{1}$ and $s_{2}$ are thin plate regression splines describing the individual effect of warming and sediment, te is tensor product smooth term modelling the interaction between warming and sediment and $\varepsilon$ is the Gaussian error term. Smoother terms were selected through a generalized cross validation procedure. The number of knots was set to 4 , which corresponded to the number of levels of predictors variables. Model assumptions were assessed visually using plots of residuals vs fitted values, box plots of residualsvs. experimental conditions, and QQ plots of standardized residuals vs Normal quantiles (Faraway 2016). GAM fitting was performed using the function gam of package mgcv in R 3.5.1 (Woodet al. 2016).

\section{Simulating from the response surface}

The RS experiment identified a significant nonlinear response of biofilm biomass to warming and sediment deposition (in interaction), but not for photosynthetic activity (see RESULTS - Experiment 1: Derivation of the response surface). Thus, we used the RS derived for biomass to simulate the response of biofilm to changes in warming and sediment deposition under constant and variable scenarios and for different patterns of correlation between the two stressors. These simulations allowed us to explore the interactive effects between nonlinearities and environmental variance on biofilm performance and the modulating effect of covariance. We started our simulations by generating values of biofilm biomass under constant $\left(Y_{\text {const, ij }}\right)$ and variable $\left(Y_{\mathrm{var}, \mathrm{ij}}\right)$ conditions, where $i$ indicated values of temperature $\left(T_{i}\right.$, with $i$ varying between 0 and $20{ }^{\circ} \mathrm{C}$ in steps of 0.5$)$ and $j$ the levels of sediment deposition $\left(S_{j}\right.$, with $j$ varying between 0.5 and $1.5 \mathrm{~cm}$ in steps of 0.5), resulting in a prediction grid of 164 values. Biomass values under constant conditions were simulated by simply feeding the RS with the prediction values. To simulate variable conditions, for each point in the prediction grid we generated 1,000 values of temperature and sediment deposition by sampling a bivariate normal distribution $\left(X \sim \mathcal{N}\left(\mu, \sum\right)\right)$ with mean $\mu=$

) (and covariance $\sum=$

$\left(\rho \sigma_{T} \sigma_{S} \quad a m p ; \sigma_{S}^{2}\right)$, where $\mu_{T}$ and $\mu_{S}$ corresponded to the chosen prediction values, $\rho$ defined the strength of correlation between predictors and $\sigma_{T}$ and $\sigma_{S}$ were the standard deviations of temperature and sediment thickness estimated from field measurements during the experiment $\left(\sigma_{T}=4.54{ }^{\circ} \mathrm{C}\right.$ and $\left.\sigma_{S}=0.41 \mathrm{~cm}\right)$. We used the mean over the 1,000 simulations to obtain the predicted value of biofilm biomass for each combination of temperature and sediment deposition from the RS. This procedure was repeated for different values of correlation $(\rho)$ ranging from negative to positive (from -1 to 1 , with increments of 0.2 ).

In addition to recording changes in biofilm biomass in the various scenarios, we used the simulated values to compute the total variance effect (TVE), a quantity that summarizes the effect of variance and correlation between stressors (Koussoroplis \& Wacker 2016). The TVE (in percentage) for a given combination of warming $i$ and sediment deposition $j$ was computed as:

$\operatorname{TVE}(\%)=\frac{Y_{\text {var, ij }}-Y_{\text {const, }} \text { ij }}{Y_{\text {const, ij }}} \times 100$ Eq. 2.

This metric expressed the standardized percentage difference of biomass under variable conditions compared to constant ones. Therefore, negative values of TVE corresponded to lower values of biomass under variable 
than constant conditions, resulting in a negative effect of variance on biomass. The opposite applied to positive values of TVE. To facilitate interpretation, the degree of covariation between warming and sediment deposition was expressed as Pearson correlation (Cor).

\section{Experiment 2: testing predictions}

Simulations generated quantitative predictions on the nonlinear response of biofilm biomass to changes in variance and correlation between warming and sediment deposition. We tested some of these predictions in a second experiment in which we manipulated the intensity and spatial correlation between stressors. In August 2019, we marked 12 experimental transects each consisting of three contiguous quadrats $(40 \times 40 \mathrm{~cm})$ in areas originally covered by biofilm (Fig. S1d). We manipulated spatial correlation by exposing the three quadrats in each transect to various combinations of warming and sediment deposition. The experiment had a factorial design with two levels of correlation $(+1$ and -1$)$ crossed with two levels of intensity (low: $+5{ }^{\circ} \mathrm{C}$ of warming and $0.5 \mathrm{~cm}$ of sediment deposition; high: $+15^{\circ} \mathrm{C}$ of warming and $1.5 \mathrm{~cm}$ of sediment deposition). In the positive correlation treatment, high (low) temperatures coincided with high (low) levels of sediment deposition across quadrats in a transect, whereas in the negative correlation treatment low (high) warming coincided with high (low) levels of sediment deposition (Fig. 1d). The designated levels of correlation were obtained by sampling paired values of temperature and sediment for the three quadrats in a transect from a bivariate normal distribution (Fig. 1d and Fig. S1c-d). Since the correlation values generated by this procedure could differ substantially from nominal values due the limited number of samples (three pairs of values for each transect), the randomly generated sequences were adjusted to obtain the desired degree of correlation.

To compute the TVE, each of the four combinations of intensity and correlation of stressors was matched with an independent set of three replicate transects with the same intensity, but with zero spatial covariance. These treatments provided the constant condition at the denominator of Eq. 2 and were obtained by imparting the same levels of warming and sediment deposition across the three quadrats in a transect. We recognize that although these treatments had zero nominal covariance, the realized correlation in any individual transects could differ from zero owing to small variation in treatments levels across quadrats. Nevertheless, since Eq. 2 uses the mean values of biofilm biomass across treatments, it is the realized mean correlation that must be close to zero. We verified this expectation by recording the amount of warming and sediment deposition imparted to all quadrats during the experiment and computing the corresponding correlation values (Fig. S4).

Chl $a$ was used as a surrogate for biofilm biomass and was measured after 10 and 18 days since the beginning of the experiment as described above (Experiment 1: derivation of the response surface). Treatment effects were evaluated with Linear Mixed Effect Models (LMEM), using the time-averaged values of Chl $a$ or (TVE) in each quadrat (Bates et al. 2015). In the model, Correlation (with two levels: -1 and +1 ), Intensity (with two levels: Low and High) and their interactions (Correlation x Intensity) were included as fixed effects, while Transects were included as a random effect to account for the lack of statistical independence among quadrats. Post-hoc contrasts between treatments were performed using the 'emmeans' package in R (Lenth et al. 2018). We evaluated model assumptions using standard graphical procedures. $95 \%$ confidence intervals (CIs) were computed for each experimental condition using non-parametric bootstrapping and were used to assess the convergence of experimental and predicted values of biomass and TVE. The bootstrap procedure involved resampling with replacement each experimental condition 1,000 times. The $95 \%$ CIs were then calculated as twice the Standard Deviation (SD) of the bootstrapped values.

Data and R-script used in this study are available from Figshare (temporary URL:https://figshare.com/s/8c67d18ec9705d8b84fa).

\section{RESULTS}

\section{Experiment 1: Derivation of the response surface}

Warming and sediment deposition interactively affected biofilm biomass (GAM: Wald Warm $\times$ Sed $=1.09, p<$ 
0.01; Fig. 2a, Tab. S1). The RS showed four distinct regions with contrasting nonlinear responses of biofilm biomass to warming and sediment deposition. A concave-down relation was evident at low to moderate levels of sediment deposition $(0-0.5 \mathrm{~cm})$ and warming $\left(0-10{ }^{\circ} \mathrm{C}\right)$ and at intermediate sediment deposition $(1 \mathrm{~cm})$ and extreme warming $\left(15^{\circ} \mathrm{C}\right)$ (Fig. 2a). In contrast, a concave-up relation was evident at low to moderate levels of warming $\left(0-10{ }^{\circ} \mathrm{C}\right)$ and at moderate to extreme levels of sediment deposition $(1-1.5 \mathrm{~cm})$ and, to a less extent, under extreme warming and low sediment deposition (Fig. 2a).

Cross-sections of the RS indicated the prevalence of a declining, almost linear relations between biomass and warming for all but the most extreme level of sediment deposition, where the relation became positive (Fig. 2b). In contrast, biomass changed nonlinearly with sediment thickness for all but the intermediate level of warming (Fig. 2c). The relation was concave-down at low to moderate levels of warming and sediment deposition, becoming concave-up at the most extreme level of sediment thickness. The opposite was observed under extreme warming (Fig. 2c).

Neither dark nor light yield exhibited a significant relationship with warming and sediment deposition (Fig. S5, Tab. S2).

\section{Simulations}

The strength and direction of correlation between warming and sediment deposition modulated the compounded effect of these stressors on biofilm biomass (Fig. 3). At the lowest level of sediment deposition (0.5 $\mathrm{cm}$ ), biofilm biomass exhibited a slight positive relationship with the degree of correlation between the two stressors, while at the intermediate level of sediment thickness $(1.0 \mathrm{~cm})$, biofilm showed no variation along the correlation gradient (Fig. 3a,b). Under extreme sediment deposition $(1.5 \mathrm{~cm})$, biomass drastically decreased with increasing correlation, collapsing at high levels of warming (Fig. 3c). Warming reduced biofilm biomass across all levels of sediment deposition (Fig. 3a-c).

Fluctuating conditions of low to moderate warming $\left(0-10{ }^{\circ} \mathrm{C}\right)$ and low sediment deposition depressed biofilm biomass compared to a constant environment, whereas environmental variability became beneficial to biofilm at larger temperatures $\left(18-20{ }^{\circ} \mathrm{C}\right)$, determining a shift from a negative to a positive TVE (Fig. 4a). This trend reversed at the intermediate level of sediment deposition, with the TVE declining consistently along the warming gradient (Fig. 4b). The TVE exhibited a funnel-shaped pattern along the warming gradient at the extreme level of sediment deposition, with negative (positive) correlation driving positive (negative) effects of variance on biofilm biomass (Fig. 4c). Overall, the effect of a negative correlation between stressors on the TVE shifted from negative to positive with increasing levels of sediment deposition (compare Fig. 4a with 4c).

\section{Experiment 2: Testing predictions}

The impact of warming and sediment deposition on biofilm was strongly modulated by the degree of spatial correlation between these stressors (Fig. 5a). The analysis identified a significant interaction between correlation and treatment intensity (LMEM ANOVA for the Correlation $\mathrm{x}$ Intensity interaction: $F_{1,12}=$ $6.18, \mathrm{p}<0.05$; Fig. 5a, Tab. S3). Negative correlation increased significantly biofilm biomass compared to the positive correlation treatment at high intensity of warming and sediment deposition, whereas the opposite (not significant) pattern occurred when the two stressors were imparted at low intensity (Fig. 5a, post-hoc contrasts, Tab. S3). These results were qualitatively similar to the expectations originating from simulations, although biofilm biomass was statistically undistinguishable (overlapping CIs) from predicted values in the positive and negative correlation treatment at low and high intensity of warming and sediment deposition, respectively (Fig. 5a). In agreement with the outcomes of simulations, negative correlation was beneficial to biofilm biomass under the most stressful conditions, whereas the opposite was observed under low intensity of warming and sediment deposition (Fig. 5a).

Similarly to what observed for biofilm biomass, spatial correlation and treatment intensity interactively affected the TVE, (LMEM ANOVA for the Correlation $\mathrm{x}$ Intensity interaction: $F_{1,12}=10.43, \mathrm{p}<0.01$; Fig. 5b, Tab. S3). The TVE was significantly larger for negative compared to positive correlation at high intensity 
of warming and sediment deposition, whereas the opposite (not significant) pattern was observed at low treatment intensity (post-hoc contrasts, Tab. S3). Similarly to what observed for biomass, the experimental results for the TVE matched the qualitative expectations originating from simulations; observed and expected values were statistically undistinguishable (overlapping CIs) both in the positive and negative correlation treatments at low intensity of warming and sediment deposition (Fig. 5b).

\section{Discussion}

Jensen's inequality has provided a phenomenological model for interpreting and predicting how environmental fluctuations and non-linear response functions interactively affect organism's performance (Ruel \& Ayres 1999; Denny and Benedetti-Cecchi 2012). Recent laboratory studies have extended Jensen's inequality to a multifactorial context, showing how covariation between multiple ecological drivers can shape the response of organisms to environmental fluctuations (Pincebourde et al . 2012, 2016; Koussoroplis and Waker 2016; Koussoroplis et al. 2017-2019). Consideration of multiple factors and their covariation provides a more realistic view of the performance of organisms in fluctuating environments, compared to the analysis of individual factors. Yet, empirical tests of these ideas in real-world conditions have lagged behind theory (Chesson 2012; Koussoroplis et al. 2017).

Combining simulations and field experiments, our study showed how the degree of spatial correlation between warming and sediment modulated the impact of these stressors on rocky intertidal biofilm through the total variance effect (TVE). In principle, the direction and magnitude of the TVE for a specific combination of warming and sediment deposition should reflect the degree and direction (concave-up or concave-down) of the curvature of the response surface (RS) (Denny \& Benedetti-Cecchi 2012). Jensen's inequality correctly identifies the direction of non-linear averaging effects for univariate response functions (Ruel \& Ayres 1999; Benedetti-Cecchi 2005; Foray et al. 2014; Wetzelet al. 2016). In contrast, predicting from response surfaces requires consideration of the direction and degree of correlation between variables. In our analysis, outcomes consistent with Jensen's inequality were observed for regions of the RS where deviations from linearity (i.e., the curvature) were more pronounced. Negative values of the TVE corresponded to a strong positive curvature of the RS (concave-down), such as those obtained at low and intermediate levels of sediment deposition in combination with either low or elevated warming, respectively. In contrast, positive values of the TVE were observed at intermediate levels of sediment deposition and low warming, where the RS had a strong negative curvature (concave-up). The modulating effect of spatial correlation was not strong enough to change the sign of the TVE for these combinations of stressors. (Figs. 2 and 4).

As the curvature of the RS decreased, spatial correlation became increasingly important in determining the direction of the TVE. This was particularly evident under elevated warming, either with high or low levels of sediment deposition. Jensen's inequality still had an effect in those regions of the RS, since the TVE deviated from zero in the absence of correlation between stressors. Nevertheless, the strength and direction of correlation ultimately determined the sign of the TVE when the curvature of the RS decreased. A negative correlation between stressors reversed the TVE from positive to negative under elevated warming and low levels of sediment. Perhaps more importantly, negative spatial correlation muted an otherwise strong impact of elevated warming and sediment accretion on biofilm biomass, changing the sign of the TVE from negative to positive (Fig. 4c).

Field manipulation of the spatial correlation between warming and sediment deposition generated results that were consistent with simulations. The impact of the two stressors on biofilm biomass in the high intensity and positive correlation scenario was likely a consequence of reduced availability of light and oxygen due to sediment accretion in combination with the impairment of the photosynthetic apparatus caused by thermal stress (Nakamoto et al. 2000; McKew et al. 2011; Larson \& Sundbäck 2012). On the contrary, in the negative correlation scenario, low and intermediate levels of sediment deposition could mitigate or even outweigh the adverse effects of warming through nutrient release and amelioration of desiccation stress (Larson \& Sundbäck 2012).

The observed differences among correlation scenarios might also reflect a shift in species composition. Alt- 
hough physiological responses to stress may occur within few days in microorganisms, longer periods (months) may be necessary for these effects to translate into compositional shifts (Schimel et al. 2007). In a parallel experiment, we found that changes in species composition in response to warming required at least four months to be detected (authors' unpublished data). Since the experiment presented here lasted 3 months, we are more inclined to believe that the outcomes were driven more by physiological responses than shifts in species composition within the biofilm.

Although the direct manipulation of warming and sediment reproduced the qualitative effects of intensity and spatial correlation observed in the simulations, not all effects were statistically undistinguishable (Fig. 5). The experiment underestimated biofilm biomass under low treatment intensity in the negative correlation scenario and overestimated it at high treatment intensity, regardless of the direction of spatial correlation. Similarly, experimental outcomes overestimated the TVE for high treatment intensity, regardless of the direction of spatial correlation (Fig. 5). These differences likely reflected the uncertainty associated with the estimation of the RS and the treatment means, both of which originated from field manipulations. In addition, the response-surface experiment was performed in spring, at ambient temperatures close to the thermal optimum of biofilm growth $\left(\sim 21^{\circ} \mathrm{C}\right.$ ) (Dal Bello et al. 2019), whereas the effects of spatial correlation was evaluated in fall at lower ambient temperatures. It is possible that experimental warming in spring may have displaced the biofilm from its thermal optimum resulting in a negative effect on biomass - hence the underestimation of treatments means compared to expectations - whereas the same treatment in fall may have had the opposite effect.

Climate change projections for the twenty-first century involve modifications of the spatio-temporal patterns of climate variables (Gunderson et al. 2016; Young \& Ribal 2019; Hayashida et al. 2020). The spatial context in which organisms are embedded, such as landscape and microtopographic features, strongly filter and modify the climate-change signal on the organisms (Pincebourde et al. 2016). The thermal mosaics originating from the topographic complexity of rocky intertidal shores are an example of a filtered signal (Helmuth et al. 2006). In the same vein, filtered signals may originate in a multifactorial context when topographic features generate small-scale patterns of correlation of environmental variables. As we have shown here, local patterns of correlation may play a crucial role in modulating the effect of climate extremes, ultimately influencing biofilm biomass at broader spatial scales (the entire shore). This work signals the need for researchers, resource managers and policy makers aiming at predicting the impact of multiple stressors, to account for current and possibly future spatio-temporal patterns of covariation among stressors. Black swans can occur in space as well as in time (Anderson and Ward 2018), but the spatial context is often overlooked in the analysis of ecological extremes. Spatial covariance should be explicitly incorporated into multiplestressors studies (Gundersonet al. 2016), risk-assessment framework (Côté et al. 2016; Goussen et al. 2016) and coupled environmental-physiological models (Rezende et al. 2014; Pincebourde et al. 2016). Our study shows how the inclusion of covariation between drivers can improve predictions from Jensen's inequality in real-world conditions. Further experimental work is needed to evaluate the generality of these findings in other ecosystems and over a wider range of environmental variables.

\section{ACKNOWLEDGEMENTS}

We thank Chiara Ravaglioli for constructive comments to the manuscript and Caterina Mintrone for field and technical assistance. The research was supported by the University of Pisa under projects PRA_2017_19 and PRA_2020_76.

\section{REFERENCES}

Bates, D., Mächler, M., Bolker, B. \& Walker, S. (2015). Fitting Linear Mixed-Effects Models Using lme4. $2015,67,48$.

Benedetti-Cecchi, L. (2003). The importance of the variance around the mean effect size of ecological processes. Ecology , 84, 2335-2346.

Benedetti-Cecchi, L. (2005). Unanticipated impacts of spatial variance of biodiversity on plant productivity. 
Ecol. Lett. , 8, 791-799.

Benedetti-Cecchi, L., Bertocci, I., Vaselli, S. \& Maggi, E. (2006). Temporal variance reverses the impact of high mean intensity of stress in climate change experiments. Ecology , 87, 2489-99.

Benedetti-Cecchi, L., Tamburello, L., Bulleri, F., Maggi, E., Gennusa, V. \& Miller, M. (2012). Linking patterns and processes across scales: the application of scale-transition theory to algal dynamics on rocky shores. J. Exp. Biol. , 215, 977-985.

Bernhardt, J.R., Sunday, J.M., Thompson, P.L. \& O'Connor, M.I. (2018). Nonlinear averaging of thermal experience predicts population growth rates in a thermally variable environment. Proc. R. Soc. B Biol. Sci. , 285, 20181076.

Bertocci, I., Maggi, E., Vaselli, S. \& Benedetti-Cecchi, L. (2005). Contrasting effects of mean intensity and temporal variation of disturbance on a rocky seashore. Ecology , 86, 2061-2067.

Chesson, P. (2012). Scale transition theory: Its aims, motivations and predictions. Ecol. Complex., 10, 52-68.

Côté, I.M., Darling, E.S. \& Brown, C.J. (2016). Interactions among ecosystem stressors and their importance in conservation. Proc. R. Soc. B Biol. Sci. , 283, 20152592.

Crain, C.M., Kroeker, K. \& Halpern, B.S. (2008). Interactive and cumulative effects of multiple human stressors in marine systems. Ecol. Lett. , 11, 1304-1315.

Dal Bello, M., Maggi, E., Rindi, L., Capocchi, A., Fontanini, D., Sanz-Lazaro, C., et al. (2015). Multifractal spatial distribution of epilithic microphytobenthos on a Mediterranean rocky shore.Oikos , 124, 477-485.

Dal Bello, M., Rindi, L. \& Benedetti-Cecchi, L. (2017). Legacy effects and memory loss: how contingencies moderate the response of rocky intertidal biofilms to present and past extreme events. Glob. Chang. Biol., $23,3259-3268$.

Dal Bello, M., Rindi, L. \& Benedetti-Cecchi, L. (2019). Temporal clustering of extreme climate events drives a regime shift in rocky intertidal biofilms. Ecology, 100, e02578.

Denny, M. (2017). The fallacy of the average: on the ubiquity, utility and continuing novelty of Jensen's inequality. J. Exp. Biol. , 220, 139-146.

Denny, M. \& Benedetti-Cecchi, L. (2012). Scaling Up in Ecology: Mechanistic Approaches. Annu. Rev. Ecol. Evol. Syst. , 43, 1-22.

Drijfhout, S., Bathiany, S., Beaulieu, C., Brovkin, V., Claussen, M., Huntingford, C., et al. (2015). Catalogue of abrupt shifts in Intergovernmental Panel on Climate Change climate models. Proc. Natl. Acad. Sci. , 112, E5777-E5786.

Faraway, J.J. (2016). Extending the Linear Model with $R$. Extending Linear Model with $R$. Chapman and Hall/CRC.

Foray, V., Desouhant, E. \& Gibert, P. (2014). The impact of thermal fluctuations on reaction norms in specialist and generalist parasitic wasps. Funct. Ecol. , 28, 411-423.

Goussen, B., Price, O.R., Rendal, C. \& Ashauer, R. (2016). Integrated presentation of ecological risk from multiple stressors. Sci. Rep. , 6, 36004.

Gunderson, A.R., Armstrong, E.J. \& Stillman, J.H. (2016). Multiple Stressors in a Changing World: The Need for an Improved Perspective on Physiological Responses to the Dynamic Marine Environment. Ann. Rev. Mar. Sci.

Harley, C.D.G. (2003). Abiotic stress and herbivory interact to set range limits across a two-dimensional stress gradient. Ecology, 84, 1477-1488. 
Hawkins, S.J., Pack, K.E., Hyder, K., Benedetti-Cecchi, L. \& Jenkins, S.R. (2020). Rocky shores as tractable test systems for experimental ecology. J. Mar. Biol. Assoc. United Kingdom, 100.

Hayashida, H., Matear, R.J., Strutton, P.G. \& Zhang, X. (2020). Insights into projected changes in marine heatwaves from a high-resolution ocean circulation model. Nat. Commun. , 11, 4352.

Helmuth, B., Broitman, B.R., Blanchette, C.A., Gilman, S., Halpin, P., Harley, C.D.G., et al. (2006). Mosaic patterns of thermal stress in the rocky intertidal zone: Implications for climate change.Ecol. Monogr. , 76, $461-479$.

Jensen, J.L.W. V. (1906). Sur les fonctions convexes et les inegalites entre les valeurs moyennes. Acta Math. , 30, 175-193.

Jentsch, A., Kreyling, J., Boettcher-Treschkow, J. \& Beierkuhnlein, C. (2009). Beyond gradual warming: Extreme weather events alter flower phenology of European grassland and heath species. Glob. Chang. Biol. , 15, 837-849.

Kirtman, B., Power, S.B., Adedoyin, J.A., Boer, G.J., Bojariu, R., Camilloni, I., et al. (2013). Nearterm Climate Change: Projections and Predictability. In: Climate Change 2013: The Physical Science Basis. Contribution of Working Group I to the Fifth Assessment Report of the Intergovernmental Panel on Climate Change(eds. Stocker, T.F., Qin, D., Plattner, G.-K., Tignor, M., Allen, S.K., Boschung, J., et al.). Cambridge University Press, Cambridge, United Kingdom and New York, NY, USA, pp. 953-1028.

Kordas, R.L., Dudgeon, S., Storey, S. \& Harley, C.D.G. (2015). Intertidal community responses to field-based experimental warming. Oikos , 124, 888-898.

Koussoroplis, A.-M., Pincebourde, S. \& Wacker, A. (2017). Understanding and predicting physiological performance of organisms in fluctuating and multifactorial environments. Ecol. Monogr., 87, 178-197.

Koussoroplis, A.-M. \& Wacker, A. (2016). Covariance modulates the effect of joint temperature and food variance on ectotherm life-history traits. Ecol. Lett. , 19, 143-152.

Koussoroplis, A., Schalicke, S., Raatz, M., Bach, M. \& Wacker, A. (2019). Feeding in the frequency domain: coarser-grained environments increase consumer sensitivity to resource variability, covariance and phase. Ecol. Lett. , 22, 1104-1114.

Larson, F. \& Sundback, K. (2012). Recovery of microphytobenthos and benthic functions after sediment deposition. Mar. Ecol. Prog. Ser., 446, 31-44.

Lawson, C.R., Vindenes, Y., Bailey, L. \& van de Pol, M. (2015). Environmental variation and population responses to global change.Ecol. Lett. , 18, 724-736.

Lenth, R., Singman, H., Love, J., Buerkner, P. \& Herve, M. (2018). Estimated Marginal Means, aka LeastSquares Means. R Packag. version 1.15-15, 34.

Lima, F.P. \& Wethey, D.S. (2012). Three decades of high-resolution coastal sea surface temperatures reveal more than warming. Nat. Commun., 3, 704.

Maggi, E., Rindi, L., Dal Bello, M., Fontanini, D., Capocchi, A., Bongiorni, L., et al. (2017). Spatio-temporal variability in Mediterranean rocky shore microphytobenthos. Mar. Ecol. Prog. Ser. , 575, 17-29.

McKew, B.A., Taylor, J.D., McGenity, T.J. \& Underwood, G.J. (2011). Resistance and resilience of benthic biofilm communities from a temperate saltmarsh to desiccation and rewetting. ISME J , 5, 30-41.

Murphy, R.J., Underwood, A.J. \& Jackson, A.C. (2009). Field-based remote sensing of intertidal epilithic chlorophyll: Techniques using specialized and conventional digital cameras. J. Exp. Mar. Bio. Ecol. , 380, $68-76$. 
Nakamoto, H., Suzuki, N. \& Roy, S.K. (2000). Constitutive expression of a small heat-shock protein confers cellular thermotolerance and thermal protection to the photosynthetic apparatus in cyanobacteria. FEBS Lett. , 483, 169-174.

Pincebourde, S., Murdock, C.C., Vickers, M. \& Sears, M.W. (2016). Fine-Scale Microclimatic Variation Can Shape the Responses of Organisms to Global Change in Both Natural and Urban Environments. Integr. Comp. Biol. , 56, 45-61.

Pincebourde, S., Sanford, E., Casas, J. \& Helmuth, B. (2012). Temporal coincidence of environmental stress events modulates predation rates.Ecol. Lett. , 15, 680-688.

Rezende, E.L., Castaneda, L.E. \& Santos, M. (2014). Tolerance landscapes in thermal ecology. Funct. Ecol. , 28, 799-809.

Ruel, J.J. \& Ayres, M.P. (1999). Jensen's inequality predicts effects of environmental variation. Trends Ecol. Evol. , 14, 361-366.

Schimel, J., Balser, T.C. \& Wallenstein, M. (2007). Microbial stress-response physiology and its implications for ecosystem function. Ecology .

Schneider, C.A., Rasband, W.S. \& Eliceiri, K.W. (2012). NIH Image to ImageJ: 25 years of image analysis. Nat. Methods, 9, 671-675.

Vaselli, S., Bertocci, I., Maggi, E. \& Benedetti-Cecchi, L. (2008). Effects of mean intensity and temporal variance of sediment scouring events on assemblages of rocky shores. Mar. Ecol. Prog. Ser., 364, 57-66.

Vasseur, D.A., DeLong, J.P., Gilbert, B., Greig, H.S., Harley, C.D., McCann, K.S., et al. (2014). Increased temperature variation poses a greater risk to species than climate warming. Proc Biol Sci, 281, 20132612.

Wernberg, T., Smale, D.A., Tuya, F., Thomsen, M.S., Langlois, T.J., de Bettignies, T., et al. (2013). An extreme climatic event alters marine ecosystem structure in a global biodiversity hotspot. Nat. Clim. Chang. , 3, 78-82.

Wetzel, W.C., Kharouba, H.M., Robinson, M., Holyoak, M. \& Karban, R. (2016). Variability in plant nutrients reduces insect herbivore performance. Nature, 539, 425-427.

Wood, S.N., Pya, N. \& Safken, B. (2016). Smoothing Parameter and Model Selection for General Smooth Models. J. Am. Stat. Assoc., 111, 1548-1563.

Young, I.R. \& Ribal, A. (2019). Multiplatform evaluation of global trends in wind speed and wave height. Science (80-. ). , 364, 548-552.

Zhang, Z., Yan, C., Krebs, C.J. \& Stenseth, N.C. (2015). Ecological non-monotonicity and its effects on complexity and stability of populations, communities and ecosystems. Ecol. Modell., 312, 374-384.

\section{LEGEND TO FIGURES}

Figure 1. Flow chart illustrating the main steps of the study. (a) To derive a response surface, we performed a fully-factorial experiment crossing four warming intensities $(+0 \operatorname{deg} C,+5 \operatorname{deg} C,+10 \operatorname{deg} \mathrm{C}$ and $+15 \mathrm{deg} \mathrm{C}$ with respect to ambient air temperature) with four levels of sediment deposition $(0 \mathrm{~cm},+0.5$ $\mathrm{cm},+1.0 \mathrm{~cm}$ and $+1.5 \mathrm{~cm}$ thick layers of sediment deployed over the plots). (b) Hypothetical warming and sediment response surface. The experimentally-derived response surface was then used to generate predictions of biofilm performance under variable (B(Warm., Sed.)) and constant conditions ((Warm., Sed.)) for different scenarios of warming-sediment covariation. (c) Based on theoretical predictions, we designed a fieldexperiment to assess the effect of warming-sediment covariation on biofilm performance. The experimental design included two crossed factors: Correlation (fixed; 2 levels: positive $(+1)$ and negative $(-1)$ ) crossed with Intensity (fixed; 2 levels: Low $(+5 \operatorname{degC}$ and $0.5 \mathrm{~cm})$ and High $(+15 \operatorname{deg} \mathrm{C}$ and $1.5 \mathrm{~cm})$ ). Experimental units (transects) consisted of three contiguous quadrats of $40 \mathrm{x} 40 \mathrm{~cm}$. We mimicked spatial covariation exposing each quadrat of a transect to different combinations of temperature and sediment depositions. We also 
established six additional transects for each of the two levels of intensity (High and Low), in which stressor intensity was maintained constant across the whole transect ("constant condition"; not shown). These transects served as a reference condition to calculate the Total Variance Effect (TVE).

Figure 2. Chlorophyll $a$ as a function of warming ([?]T) and sediment deposition. Warmingsediment response surface (RS). (a) Curvature was calculated as the numerical approximation of the second derivative. Positive values (blue) reflect a locally concave-down curvature of the RS, while negative values (red) indicate a locally concave-up curvature. Mean $+\mathrm{SE}(n=4) \mathrm{Chl} a$ for each warming-sediment combination. Cross sections of the response surface at three sediment deposition (b) and warming levels (c).

Figure 3. Biomass simulations under different correlation scenarios between warming and sediment deposition. The variance effect of warming and sediment deposition on biomass was simulated by GAM and response surfaces at various warming-sediment covariances, mean sediment thickness $(+0.5$ $\mathrm{cm},+1.0 \mathrm{~cm},+1.5 \mathrm{~cm})$ and mean temperature $(0 \operatorname{deg} \mathrm{C},+5 \operatorname{deg} \mathrm{C},+10 \operatorname{deg} \mathrm{C},+15 \operatorname{deg} \mathrm{C},+20 \operatorname{deg})$. In different simulations, correlation ranged from -1 to 1 . Black points indicate the values of warming, sediment deposition and their correlation chosen as treatment levels for the subsequent experimental test of simulation predictions.

Figure 4. Total variance effect (TVE). Joint warming-sediment variance and correlation effects on biofilm biomass ( $\mu \mathrm{g} \mathrm{chl} a \mathrm{~cm}^{-2}$ ) as a function of warming ([?]T) at each of three levels of sediment deposition: $0.5 \mathrm{~cm} \mathrm{(a),} 1.0 \mathrm{~cm}$ (b) and $1.5 \mathrm{~cm}$ (c). The TVE expresses the relative percent change of biofilm biomass $(\mathrm{Chl} a)$ under variable conditions with respect to constant conditions for a given combination of sediment and warming.

Figure 5. Testing predictions. Predicted vs experimental values of biomass $\left(\mu \mathrm{g} \mathrm{chl} a \mathrm{~cm}^{-2}\right)$ as a function of correlation and intensity of warming and sediment deposition. Yellow and dark-green filled circles indicate mean biofilm biomass under negative and positive correlation, respectively $(n=4)$. Grey circles refer to mean biomass under constant conditions $(n=3)$. Yellow and dark-green empty squares are the expected values of biofilm biomass obtained from simulations under low $\left([?] \mathrm{T}=+5^{\circ} \mathrm{C}\right.$ and sediment deposition $\left.=0.5 \mathrm{~cm}\right)$ and high $([?] \mathrm{T}=+15 \operatorname{deg} \mathrm{C}$ and sediment deposition $=1.5 \mathrm{~cm})$ intensity, respectively. Error bars are nonparametric bootstrapped $95 \%$ confidence intervals.

Figure 1 Figure 2 Figure 3 Figure 4 Figure 5

\section{Hosted file}

Supporting_information.pdf available at https://authorea.com/users/412256/articles/521008spatial-covariance-reverses-the-compound-effect-of-multiple-stressors-on-rocky-shorebiofilm 